\title{
Article
}

\section{Cognitive Bias in Emissions Trading}

\author{
Jae-Do Song ${ }^{1}$ and Young-Hwan Ahn ${ }^{2, *}$ \\ 1 College of Business Administration, Chonnam National University, Gwangju 61186, Korea; \\ sjaedo@chonnam.ac.kr \\ 2 Korea Energy Economics Institute, 405-11 Jongga-ro, Jung-gu, Ulsan 44543, Korea \\ * Correspondence: ahn@keei.re.kr; Tel.: +82-52-714-2175; Fax: +82-52-714-2026
}

Received: 8 February 2019; Accepted: 27 February 2019; Published: 5 March 2019

\begin{abstract}
This study investigates whether cognitive biases such as the endowment effect and status quo bias occur in emissions trading. Such cognitive biases can serve as a barrier to trade. This study's survey-based experiments, which include hypothetical emissions trading scenarios, show that the endowment effect does occur in emissions trading. The status quo bias occurs in only one of the three experiments. This study also investigates whether accumulation of experience can reduce cognitive bias as discovered preference hypothesis expects. The results indicate that practitioners who are supposed to have more experience show no evidence of having less cognitive bias. Contrary to the conventional expectation, the practitioners show significantly higher level of endowment effect than students and only the practitioners show a significant status quo bias. A consignment auction situation, which is used in California's cap-and-trade program, is also tested; no significant difference between general permission trading and consignment auctions is found.
\end{abstract}

Keywords: emissions trading; cognitive bias; consignment auction; climate policy

\section{Introduction}

Emissions trading allows entities to achieve emission reduction targets in a cost-effective way through buying and selling emission allowances in emissions trading markets [1,2]. Each trade transaction results in Pareto improvement; the more deals that are made, the more positive the results. However, transactions seem insufficient, especially in the early stage of emissions trading schemes like Korea Emissions Trading Scheme (ETS) and China ETS [3-5]. Identifying the reasons for this transaction insufficiency is important.

The literature has attempted to explain why emissions trading is sluggish by discussing the problems faced by the institutions involved and participating companies $[3,4,6,7]$. Previous studies, however, generally assume these participants have been rational decision makers. The behavioral economics perspective, which can provide new implications by introducing the concept of 'cognitive bias,' has not been adequately considered in the setting of emissions trading. Cognitive bias happens because people depend on intuitive, rapid, and automatic heuristics [8] to 'reduce the complex tasks of assessing probabilities and predicting values to simpler judgmental operations' [9] in their information processing and decision making. Heuristics are very different from rational processing, which is analytic, conscious, and rule-based. Thus, a view that assumes rational decision makers leads to an understanding of the problem and a presentation of solutions that differ widely from those that flow from a view that acknowledges cognitive bias. It is worthwhile trying to understand the problem by using both perspectives.

Some literature discusses the endowment effect and status quo bias to explain the sluggishness of emissions trading $[4,6,10,11]$. However, the literature has only treated these cognitive biases as a possibility and has not verified their effects using empirical methods in the setting of emissions trading. 
Although environmental economists have used laboratory experiments to examine various design choices for emissions trading schemes such as price ceiling, banking, type of auctions, and so on [12,13], they have not directly dealt with cognitive biases. It is important to note that cognitive biases do not always occur. For example, if goods are expected to be resold, the endowment effect tends not to occur $[6,14]$. Emission allowances do not generate usage value in themselves. The allowances are a kind of permits to emit emissions to the level of the overall limit and have some similar characteristics to financial assets [15]. As Kahneman et al. [14] argues, cognitive biases such as the endowment effect may not occur in an asset of this nature. This study attempts to test whether the endowment effect or status quo bias happen in the setting of emissions trading using a survey-based experiment.

In addition, several researchers have argued for the 'discovered preference hypothesis,' whereby the endowment effect disappears as people become more experienced in a certain decision environment [16-20]. According to this proposition, even if nonprofessional decision makers such as students show an endowment effect or status quo bias, we may assume that the practitioners in charge of emissions trading, who fully understand and have experiences of the system, may show no or less cognitive biases. Therefore, this study also tests whether cognitive bias can be reduced through accumulation of experience by comparing experiment results for two different groups of university students and emission trading practitioners in ETS participating firms.

Another way to reduce cognitive bias may be introduction of consignment auctions as are used in the California's cap-and-trade program, which was launched on January 1, 2012 with an enforceable compliance obligation beginning with 2013 greenhouse gas emissions. California is part of the Western Climate Initiative (WCI) which began in 2007 with an agreement of the governors of Arizona, California, New Mexico, Oregon, and Washington to develop regional greenhouse gas reduction targets and develop a market-based program to meet their targets. In the WCI, California, Quebec, and Ontario are currently running their cap-and-trade programs [21]. The California's cap-and-trade program has adopted the consignment auction for $\mathrm{CO}_{2}$ allowances from its beginning for ensuring price discovery and directing allowance value to intended uses [11]. The consignment auction combines free allocation and auctioning into one mechanism. Allowances are initially endowed to firms through a free allocation rule. Then, firms consign their initial allowances to the auctioneer. In the auction, firms submit their demand schedules and the overall clearing price is determined. Firms pay the clearing price if the equilibrium allocation of allowances in the auction is more than their original allocation and obtain revenue if the equilibrium allocation is less than their original allocation. Thus, all auction revenue is diverted to the holders of the initial allowance endowments. This novel initial allocation process has been regarded as being both politically appealing and successful in generating clear price discovery $[10,11,22-24]$.

Consignment auctions may reduce the endowment effect, as they require a transaction as soon as emission allowances are initially allocated. In addition, whether participants possess the allocated allowances or not (the status quo) is ambiguous before the consignment auction, which may reduce the status quo bias. Therefore, this study compares experiment results with a consignment auction to those without to investigate whether consignment auctions can reduce cognitive biases.

In sum, the objective of this study is to investigate the existence of the cognitive biases in the setting of emissions trading and the effects of accumulation of experiences and the consignment auction on the biases. To fulfill the objective, this study examines (1) whether the endowment effect and status quo bias occur in emissions trading situations, (2) whether practitioners show less cognitive bias than students, and (3) whether the endowment effect and status quo bias can be reduced in consignment auction situations. Experiments for second and third purpose also serve to verify the endowment effect and status quo bias repetitively. To our knowledge, this study is the first attempt to empirically test cognitive biases in the setting of emissions trading.

This paper is organized as follows. In Section 2, we suggest hypotheses and their meanings for cognitive bias in emissions trading. In Section 3, we then introduce the structure of the experiment to test the hypotheses. Section 4 shows the results of the experiment and the analysis. In Section 5 , 
we discuss the implications of the results in real situations. Finally, in Section 6, we provide conclusions and some limitations of this study.

\section{Literature Review and Research Hypotheses}

\subsection{Endowment Effect}

When the endowment effect exists, willingness-to-accept (WTA), the minimum amount of money that people are willing to accept to abandon a good, is systematically higher than willingness-to-pay (WTP), the maximum amount people are willing to sacrifice to procure a good [25]. In other words, people ascribe more value to things merely because they own them.

The endowment effect rests on a hypothesis concerning the psychology of preferences associated with prospect theory that predicts loss aversion $[19,25]$. In loss aversion, losses are perceived to be greater than gains of equal magnitude. When people sell an object, the lost object is perceived as a loss. Thus, the lost value (WTA) is perceived to be higher than the earned value (WTP) when they buy the same object. Knetsch and Sinden [26], Kahneman, Knetsch, and Thaler [27] have shown the existence of the endowment effect through experiments using general consumer goods, such as mugs and chocolate bars. Kahneman et al. [14] have also revealed the effect using public goods that are not traded in the market, such as postal services and park trees.

Further, the concept of endowment effect has been applied in various settings. Frenkel, Heller, and Teper [28] showed that endowment effect offset the winner's curse, which indicates overpayment of buyer in common value auction. Penon and Ortega [29], meanwhile, applied an endowment effect to the problem of firm ownership. In addition, some previous literature has mentioned the endowment effect in emissions trading $[4,6,10,11]$. However, the literature has only treated these cognitive biases as a possibility and has not verified their effects using empirical methods in an emissions trading situation.

A series of related studies has examined the factors determining endowment effect levels. Novemsly and Kahneman [30] showed that money given up in purchases is not generally subject to loss aversion and thus does not create an endowment effect. Kahneman et al. [14] argued that the endowment effect does not occur if the goods involved are expected to be resold. In their study, no endowment effect was observed for tokens that were to be exchanged for cash after the experiment. Horowitz and McConnell [25] showed that WTA is generally about seven times higher than WTP and that this ratio is lower for commodities traded on the market and greater for non-market goods such as public and environmental goods. Many other studies have found variables that moderate endowment effect levels. Hedonic goods have been found to generate more of an endowment effect than utilitarian goods [31]; high involvement has been found to generate more of an endowment effect [32]; emotions such as disgust and sadness have been found to reduce it [33-35]; and low level of empowerment to decision maker incurs more endowment effect [36].

Allowances do not generate utility in themselves; they do so by eliminating fines due to actual emissions or by selling them. Thus, allowances are a kind of claim and have characteristics similar to financial assets [15]. As Novemsly and Kahneman [30], Kahneman et al. [14], and Horowitz and McConnell [25] suggest, allowances may not cause an endowment effect. Kreutzer [6] argues that, even if allowances are not held solely for resale, the existence of reasonably active spot markets for allowances means that they can easily be converted into cash at any time. This easy conversion into cash may reduce the endowment effect. Therefore, this study tests whether the endowment effect occurs in emissions trading using the following hypothesis:

Hypothesis 1. In emissions trading, WTA for allowances will be higher than WTP.

List [37] argued that 'prospect theory, which explains endowment effect and status quo bias, adequately organizes behavior among inexperienced consumers, but consumers with intense market experience behave largely in accordance with neoclassical predictions.' Plott and Zeiler $[19,20]$ listed five factors that can eliminate the endowment effect: an explanation of the optimal response, 
the provision of practice rounds, incentive compatibility with the elicitation mechanism, the mechanism used to elicit valuation, and the gap measurement method. Among those, provision of practice rounds is also related to experience.

This study compares endowment effect levels between students and emissions trading practitioners, who have accumulated trading experience and understand the trading system well and thus are expected to be better decision makers. Given the findings of List [37], Plott, and Zeiler [19,20], practitioners should show either no endowment effect or a smaller effect than is observed in the students. Thus, the following is proposed:

Hypothesis 2. Emissions trading practitioners will show less of a gap between WTA and WTP than is observed in students.

Consignment auctions may reduce the endowment effect since they require a consignment to the auctioneer before allocated emission allowances can be held. Knetsch [38] showed that an endowment effect occurred only when the subjects owned the goods for a while before they were told they could trade them. Thus, an endowment effect may not occur before a consignment auction is completed. The following is therefore hypothesized:

Hypothesis 3. Consignment auctions generate less of a gap between WTA and WTP than general emissions trading does.

The endowment effect in emissions trading would make firms with excess allowances want to sell at relatively high prices, while firms needing additional allowances would want to purchase at relatively low prices. This could reduce transactions. Hypothesis 1, Hypothesis 2, and Hypothesis 3 assume individual actors rather than organizational ones. If firm decisions differ from those made by individuals, then the hypotheses may not apply to firms. However, this study assumes that firm decisions depend on decisions made by practitioners and executive officers and that firm decisions may not be free of the cognitive biases of individuals if they are held by the majority. This intuition is consistent with the perspective taken by organizational studies. The Echelons theory, proposed by Hambrick [39] and Hambrick and Mason [40] (and widely accepted by organization theorists), argues that executives' experiences, values, and personalities greatly influence their interpretation of the situations they face and, in turn, affect their choices.

The sections below deal with hypotheses on status quo bias. These consider the bias at the individual level, but such bias ultimately affects firm-level decision making.

\subsection{Status Quo Bias}

Kahneman et al. [14] argued that 'one implication of loss aversion is that individuals have a strong tendency to remain at the status quo, because the disadvantages of leaving it loom larger than advantages.' Samuelson and Zeckhauser [41] showed that defining a particular investment alternative as the status quo increases the likelihood of that alternative being selected. Hartman, Doane, and Woo [42] showed the effect of status quo bias by examining electric power services that differed in reliability and price. The concept of status quo bias also has been used to explain why new services or policies are not accepted by people [43,44]. Further, Kreutzer [6] argued that loss aversion and status quo bias can inhibit emissions trading.

The endowment effect and status quo bias both come from loss aversion. Thus, as with the endowment effect, allowances may not cause status quo bias since they are a kind of claim $[14,25,30]$. This study tests whether status quo bias occurs in emissions trading.

Status quo bias is a situation in which a prior situation (status quo) affects a choice. If status quo bias occurs during a transaction that offers a choice between an excess-allowances situation (EAS) and lack-of-allowances situation (LAS), firms will stay in the EAS when facing an excess-allowances-prior situation (EApS, where the amount of allocated allowances is greater than what is needed); contrariwise, 
firms will not choose EAS in a lack-of-allowances-prior situation (LApS). Thus, the following is hypothesized:

Hypothesis 4. When subjects can choose between an EAS and LAS through a transaction, the EAS will be chosen more often by subjects coming from an EApS than by subjects coming from a LApS.

As List [37], Plott, and Zeiler [19,20] suggested, emissions trading practitioners with a longer experience and better understanding of the trading system may not show status quo bias, as with the endowment effect. Further, some studies explained that people choose status quo bias to avoid a difficult decision $[41,45,46]$. Then, practitioners who become accustomed to the emission trading context can make more structured decisions with less difficulty. As a result, they may show less status quo bias. Thus, the following is hypothesized:

Hypothesis 5. The gap in the ratio of subjects who choose EAS between subjects with EApS and subjects with LapS will be lower when the subjects are emissions trading practitioners than when the subjects are general students.

Furthermore, in consignment auctions, firms are allocated allowances but must consign them to the auctioneer and purchase them again, though they do not pay for the initially allocated amount. Then, the status quo (whether they possess the allocated allowances) is ambiguous in the pre-consignment period. Thus, consignment auctions may induce less status quo bias and the following hypothesis is proposed:

Hypothesis 6. The gap in the ratio of subjects who choose EAS between those with EApS and those with a LApS is smaller in consignment auctions than in general emissions trading situations.

\section{Experiment Design}

\subsection{Outline of Experiments}

This study carried out several survey-based experiments. To test Hypothesis 1 (on the endowment effect), WTA is measured via EAS, and WTP is measured via LAS. Then, the WTA and WTP results are compared. To test Hypothesis 2, two similar experiments involving students and practitioners in a general emissions trade scenario (GETS) are compared. For Hypothesis 3, two different scenarios, one for GETS and another for consignment auctions (CAS), are run with students. Thus, for Hypothesis 1 , Hypothesis 2, and Hypothesis 3, the study employed a 2 (WTA vs. WTP) $\times 3$ (students and GETS vs. practitioners and GETS vs. students and CAS) between-subjects design.

To test Hypothesis 4, dealing with status quo bias, the decision of whether to accept a transaction (i.e., to stay at status quo) was tested with EAS (sales situation) and LAS (purchase situation); the two results were then compared. To test Hypothesis 5 and Hypothesis 6, a design similar to that used to test Hypothesis 2 and Hypothesis 3 was employed. Thus, a 2 (EAS and LAS) $\times 3$ (students and GETS vs. students and CAS vs. practitioners and GETS) between-subjects design was used to test the hypotheses on status quo bias.

\subsection{Scenarios and Questions for Endowment Effect}

In each experiment, the subjects were asked to assume they were the CEO of a firm and to answer questions after scenarios and questions were presented. The GETS section for WTA appeared as follows:

'Your firm has been assigned 500,000 tons of allowances from the government for one year from today and your firm estimates 400,000 tons of emissions over the year. You are currently considering selling 100,000 tons of spare allowances on the emissions trading market. 
The actual amount of emissions over the year may fluctuate from 400,000 tons. If the amount of allowances (400,000 tons or 500,000 tons) determined by the trade exceeds the total amount of your emissions after one year, you will sell the spare allowances at the market price at that time. If it does not, you will purchase the deficit amount at the market price at that time. The market price at that time is expected to be $17,000-27,000 /$ ton.

Question: What is the minimum price at which you are willing to sell your 100,000 tons of spare allowances now? /ton.'

The WTP section was created by changing the underlined words: ' 400,000 tons' to ' 600,000 tons,' 'sell' to 'purchase,' 'spare allowances' to 'deficit allowances,' ' 400,000 tons or 500,000 tons' to '500,000 tons or 600,000 tons,' and 'minimum' to 'maximum.' These two GETS questionnaires (for WTA and WTP) were distributed to both students and practitioners.

Next, the CAS section for WTA appeared as follows:

'Your firm has been assigned 500,000 tons of allowances from the government for one year from today, and your firm estimates 400,000 tons of emissions over the year.

In this situation, before the firm holds the assigned allowances, the firm has the obligation to entrust the whole amount of allowances to the auctioneer to be auctioned. If you only need 400,000 tons, you will be bidding 400,000 tons and get 400,000 tons with additional revenue $(100,000$ tons $\times$ the final contract price). You are receiving the additional revenue that corresponds to the gap between 500,000 and 400,000 (100,000 tons) because you originally had 500,000 tons of allowances. If you want, you can get 500,000 tons with no additional revenue.

The actual amount of emissions over the year may fluctuate from 400,000 tons. If the amount of allowances $(400,000$ tons or 500,000 tons) determined by the result of the auction exceeds the total amount of your emissions after one year, you will sell the spare allowances at the market price at that time. If it does not, you will purchase the deficit amount at the market price at that time. The market price at that time is expected to be $17,000-27,000 /$ ton.

Question: What is the minimum price at which you are willing to sell your 100,000 tons of spare allowances in the consignment auction? /ton.'

The WTP section was created by making changes similar to those made for the GETS section. The two CAS questionnaires (for WTA and WTP) were distributed only to students.

\subsection{Scenarios and Questions for Status Quo Bias}

The two different prior situations, EApS (sales situation) and LApS (purchase situation), were presented to the subjects after the basic explanation of emissions trading and their decisions on whether to accept an offer of transaction were tested. The EApS section for GETS appeared as follows:

'Your firm has been assigned 600,000 tons of allowances from the government for one year from today and your firm estimates 400,000-600,000 tons of emissions over the year. In this situation, another firm asks you to sell 200,000 tons of allowances. In this deal, there is no transaction cost.

If the amount of your allowances (400,000 tons or 600,000 tons) determined by the trade exceeds the total amount of your emissions after one year, you will sell the spare allowances at the market price at that time. If it does not, you will purchase the deficit amount at the market price at that time. The market price at that time may be different from what it is now.

Question: Will you accept the offer? (Yes or No)'

In the scenario for the endowment effect, the question asked the level of price and, to guide the answer, we provided information on expected price levels. For the status quo bias, however, we asked the binary question on whether to accept or not the offer. Thus, information on expected price levels is not necessary and the scenario mentioned only the possibility that the price could be changed.

The LApS scenario was created by making only two changes: changing ' 600,000 tons' to '400,000 tons' and 'sell' to 'purchase.' The two GETS questionnaires (for EApS and LApS) were distributed to both students and practitioners. Next, to create the consigned auction scenario, a passage in the GETS section ('In this situation, another firm asks you to sell 200,000 tons of allowances. In this 
deal, there is no transaction cost') was changed to reflect the characteristics of the consignment auction (as in the experiments on the endowment effect). The two CAS questionnaires (for EAS and LAS) were distributed only to students.

\subsection{Distribution of the Questionnaire}

Four sets of questionnaires were used for the students. Each questionnaire had four questions. The first verified whether the subject understood the scenario, since the responses of subjects who did not fully understand the scenarios had to be excluded from the analysis. To check their understanding, the same WTA/WTP scenarios used in experiment for endowment effect were presented; the firm's choice, future total emission amounts, and future price were additionally presented. Finally, the subjects were asked how much they would pay (earn) now and in one year. The second question was about the endowment effect and the WTP/WTA scenarios. The third question was about status quo bias and whether the subjects would accept a transaction. The fourth question was about gender and age. The four sets of questionnaires produce the following: 2 (GETS vs. CAS) $\times 2$ ('WTA and EAS (whether to accept a sales offer or not)' vs. 'WTP and LAS (whether to accept a purchase offer or not)').

For emissions trading practitioners, two sets of questionnaires were used: 'WTA and EAS' vs. 'WTP and LAS' for the same GETS. These also included the three questions described above, except the fourth about gender and age.

Management school students at a national university served as the student respondents. Each subject received one set of questionnaires during a class. For the practitioner group, the sample was collected from around 560 firms that have participated in the Korea ETS for more than three years. The practitioner respondents received questionnaires by e-mail and sent back their responses. They are mostly middle managers in the environment/energy department in the Korea ETS participating companies. Other details on the samples for each experiment are provided below.

\section{Data Analyses and the Results}

\subsection{Test of Endowment Effect}

After questionnaires with incorrect answers to the test questions were excluded, 213 responses remained. Among these, 15 did not include answers to the questions on WTA or WTP. Thus, 198 responses were used to test the endowment effect. Among the 213, one did not include an answer to the question about whether to accept a transaction, so the test on status quo bias analyzed 212 responses. Most wrong answers were given for the CAS question, reflecting the complexity of the scenario. As questionnaires with wrong answers to the test question were excluded, the results of the analyses were not affected by insincere responses. The following analyses were carried out using SPSS ver. 23 .

Table 1 shows the characteristics of the sample for the test of the endowment effect and the results of the independent sample $t$-tests. In all three experiments, WTA is higher than WTP, and the differences are significant (Students and GETS, $t=5.801, p=0.000$; Students and CAS, $t=3.783$, $p=0.000$; Practitioners and GETS, $t=13.624, p=0.000$ ). Thus, Hypothesis 1 , on endowment effect, is supported.

Hypothesis 2 concerns the moderating effect of experience on the endowment effect. In the test, a two-way ANOVA was carried out using the results of Students and GETS and Practitioners and GETS. The results are presented in Table 2. The main effect from 'WPA or WTP' is significant $(p=0.000)$ and also supports Hypothesis 1 . The interaction effect from 'WPA or WTP' and 'students or practitioner' is also significant $(p=0.047)$. However, as Table 1 shows, the gap between WTA and WTP is higher in practitioners than in students. Thus, Hypothesis 2 is not supported. 
Table 1. Endowment effect.

\begin{tabular}{ccccccc}
\hline & \multicolumn{2}{c}{ Students and GETS } & \multicolumn{2}{c}{ Students and CAS } & \multicolumn{2}{c}{ Practitioners and GETS ${ }^{+}$} \\
\cline { 2 - 7 } & WTA & WTP & WTA & WTP & WTA & WTP \\
\hline No. of & 33 & 32 & 25 & 35 & 32 & 41 \\
response & (male 19, female 14) & $(18,14)$ & $(12,13)$ & $(20,15)$ & $($ n.a. $)$ & (n.a.) \\
Average Age & 23.3 & 23.4 & 23.4 & 23.5 & n.a. & n.a. \\
WTA/WTP & $($ Min 21, Max 27) & $(20,28)$ & $(20,30)$ & $(20,26)$ & & $19,391.95$ \\
Average & $23,906.06$ & $19,500.00$ & $24,036.00$ & $20,914.29$ & $25,765.63$ & $(2,102.238)$ \\
$\begin{array}{c}\text { (standard } \\
\text { error) } \\
t \text {-test }\end{array}$ & $(3,002.701)$ & $(3,121.207)$ & $(3,361.408)$ & $(2,993.831)$ & $(1,818.296)$ & \\
\hline \multicolumn{7}{c}{} \\
\multicolumn{2}{c}{$t=5.801, \mathrm{p}=0.000^{* *}$} & $t=3.783, p=0.000 * *$ & $t=13.624, p=0.000 * *$ \\
\hline
\end{tabular}

Table 2. Moderating effect of experience on endowment effect.

\begin{tabular}{cccccc}
\hline Source & $\begin{array}{c}\text { Type III Sum } \\
\text { of Squares }\end{array}$ & DF & Mean Square & F & Sig. \\
\hline Corrected model & $1,052,437,384$ & 3 & $350,812,461.447$ & 54.046 & $0.000^{* *}$ \\
Intercept & $66,928,053,857.599$ & 1 & $66,928,053,857.599$ & $10,310.981$ & $0.000^{* *}$ \\
WTA_WTP & $991,547,289.999$ & 1 & $991,547,289.999$ & 152.758 & $0.000^{* *}$ \\
Students_practitioners & $26,177,329.416$ & 1 & $26,177,329.416$ & 4.033 & $0.047^{*}$ \\
WTA_WTP * & $33,035,185.939$ & 1 & $33,035,185.939$ & 5.089 & $0.026^{*}$ \\
Students_practitioners & $869,787,219.281$ & 134 & $6,490,949.398$ & & \\
Error & $68,558,994,900.000$ & 138 & & & \\
Total & $1,922,224,603.623$ & 137 & &
\end{tabular}

Hypothesis 3 concerns the moderating effect of consignment auctions on the endowment effect. In this test, a two-way ANOVA was also carried out using the results of Students and GETS and Students and CAS. As Table 3 shows, the main effect from 'WPA or WTP' is significant $(p=0.000)$. The interaction effect from 'WPA or WTP' and 'GETS or CAS' is not significant $(p=0.254)$. Thus, CAS does not show less of an endowment effect, and therefore Hypothesis 3 is not supported.

Table 3. Moderating effect of consignment auction on endowment effect.

\begin{tabular}{cccccc}
\hline Source & $\begin{array}{c}\text { Type III Sum of } \\
\text { Squares }\end{array}$ & DF & Mean Square & F & Sig. \\
\hline Corrected model & 464639634.978 & 3 & $154,879,878.326$ & 16.066 & $0.000^{* *}$ \\
Intercept & $59,995,207,685.074$ & 1 & $59,995,207,685.074$ & $6,223.573$ & $0.000 * *$ \\
WTA_WTP & $435,486,113.152$ & 1 & $435,486,113.152$ & 45.175 & $0.000 * *$ \\
GETS_CAS & $18,325,772.153$ & 1 & $18,325,772.153$ & 1.901 & 0.171 \\
WTA_WTP *GETS_CAS & $12,676,674.968$ & 1 & $12,676,674.968$ & 1.315 & 0.254 \\
Error & $1,166,439,245.022$ & 121 & $9,639,993.761$ & & \\
Total & $61,946,420,000.000$ & 125 & & & \\
Corrected total & $1,631,078,880.000$ & 124 & &
\end{tabular}

\subsection{Test of Status Quo Bias}

The test for status quo bias analyzed 212 responses. Table 4 shows the characteristics of the sample and the analysis results. 
Table 4. Status quo bias.

\begin{tabular}{|c|c|c|c|c|c|c|}
\hline \multirow[b]{2}{*}{ Prior situation } & \multicolumn{2}{|c|}{ Students and GETS } & \multicolumn{2}{|c|}{ Students and CAS } & \multicolumn{2}{|c|}{ Practitioners and GETS + } \\
\hline & EApS & LApS & EApS & LApS & EApS & LApS \\
\hline Responses & $\begin{array}{c}35 \\
\text { (male 20, female } \\
15)\end{array}$ & $\begin{array}{c}33 \\
(19,14)\end{array}$ & $\begin{array}{c}27 \\
(13,14)\end{array}$ & $\begin{array}{c}35 \\
(20,15)\end{array}$ & $\begin{array}{c}37 \\
\text { (n.a.) }\end{array}$ & $\begin{array}{c}45 \\
\text { (n.a.) }\end{array}$ \\
\hline Average age & $\begin{array}{c}23.3 \\
(\min 21, \max 27)\end{array}$ & $\begin{array}{c}23.4 \\
(20,28)\end{array}$ & $\begin{array}{c}23.4 \\
(20,30)\end{array}$ & $\begin{array}{c}23.5 \\
(20,26)\end{array}$ & n.a. & n.a. \\
\hline No. who choose EAS & $\begin{array}{c}25 \\
(71.4 \%)\end{array}$ & $\begin{array}{c}19 \\
(57.6 \%)\end{array}$ & $\begin{array}{c}16 \\
(59.3 \%)\end{array}$ & $\begin{array}{c}21 \\
(60.0 \%)\end{array}$ & $\begin{array}{c}37 \\
(100.0 \%)\end{array}$ & $\begin{array}{c}14 \\
(31.1 \%)\end{array}$ \\
\hline $\begin{array}{c}\text { (ratio) } \\
\text { Status quo bias } \\
\left(\chi^{2} \text { independence test }\right)\end{array}$ & \multicolumn{2}{|c|}{$\begin{array}{c}\text { Pearson } \chi^{2}=1.427 \\
p=0.232\end{array}$} & \multicolumn{2}{|c|}{$\begin{array}{c}\text { Pearson } \chi^{2}=0.003 \\
p=0.953\end{array}$} & \multicolumn{2}{|c|}{$\begin{array}{c}\text { Pearson } \chi^{2}=40.982 \\
\quad p=0.000 * *\end{array}$} \\
\hline
\end{tabular}

As Table 4 shows, the result for Students and GETS and Practitioners and GETS is what Hypothesis 4 expected: the ratio of subjects who choose EAS is higher in EApS. In Students and CAS, however, the ratio is slightly higher in LApS. Table 4 also shows the result for a chi-square independence test, wherein only Practitioners and GETS shows a significant difference (Pearson $\chi^{2}=40.982, p=0.000$ ). Thus, Hypothesis 4 is supported only for Practitioners and GETS.

Hypothesis 5 expects that practitioners will show less status quo bias. However, only the practitioner experiment (Practitioners and GETS) supports status quo bias significantly; thus, Hypothesis 5 is not supported. This result is consistent with the result on the endowment effect. In tests for both cognitive bias types, practitioners are more sensitive. Hypothesis 6 concerns the moderation effect of consignment auctions. Because status quo bias was not supported in either Students and GETS or Students and CAS, Hypothesis 6 is not supported.

\section{Discussion}

This study tested two types of cognitive bias in emissions trading situations: the endowment effect and status quo bias. The endowment effect was supported significantly in all three experiments. The status quo bias was supported significantly only in the practitioner experiment. Overall, this study shows that cognitive bias can occur in emissions trading situations, which may explain the lack of emissions trading transactions.

The finding concerning the WTA/WTP ratio is notable. Horowitz and McConnell [25] showed that the ratio of WTA/WTP is generally about seven. However, in this study, the ratio was 1.149 to 1.329. Allowances are a kind of claim and have characteristics similar to financial assets. This study's finding of a low WTA/WTP ratio is consistent with the finding in previous studies that money, commodities, and goods that are expected to be resold create a lower loss aversion and endowment effect $[14,25,30]$.

In addition, this study tested whether more experience can reduce cognitive bias. Emissions-trading practitioners, who are supposed to have much more experience and understanding of emissions trading, showed no evidence of having cognitive biases lower than those of students. In fact, practitioners showed a significantly higher endowment effect and only the practitioners showed status quo bias. Three possible explanations for these results are discussed below.

First, though practitioners have much experience in emissions trading, they might not have received adequate feedback and might not understand which kind of decisions can lead to cost minimization. The result of an emissions trading transaction depends on many factors, such as the estimate of the amount of their own emissions, the future prices of allowances, and changes in government policy. Thus, they may not perceive that cognitive bias led them to make a wrong choice. For example, even if a high valuation of their allowances came from the endowment effect, they might assume that they estimated future allowances prices incorrectly. Thus, they may not adjust their cognitive biases if their decisions are affected by many factors and are complex. However, this does not explain why practitioners show stronger cognitive biases. 
Second, firms' incentive systems for emissions trading may be the cause. If firms provide asymmetric incentives that provide penalties for loss that are higher than the rewards for gains of the same amount, practitioners will feel a level of loss aversion that is higher than what students feel. Loss aversion is the main explanation of the endowment effect and status quo bias $[14,25,30]$. Even though the questionnaires in this study asked subjects to think of themselves as the CEO, this might not fully exclude the effect of asymmetric incentives. However, this logic does not explain how this asymmetric incentive occurs. If it comes from cognitive biases such as the risk aversion or loss aversion of the organizational members, it forms a circular logic.

Third, firm members have more loss aversion than students, not only in emissions trading, but also in most decision making. Defensive or self-limiting behavior, an important issue in organizational behavior $[47,48]$, relates to risk aversion and can create an endowment effect and status quo bias that is higher than that observed in general students. The higher level of loss aversion of practitioners can be related to the concept of decision avoidance which was discussed in relation to Hypothesis $5[41,45,46]$. If practitioners feel more loss aversion, they will seek more sophisticated decision process and feel more difficulty in decision making even though they have more experience than students. If the higher level of loss aversion occurs because of the general organizational culture, reducing cognitive biases such as the endowment effect and status quo bias may be very difficult. However, firms should be aware of the possibility of cognitive biases and try to reduce them by exercising additional caution and providing education.

In addition, this study tested whether consignment auctions can reduce the endowment effect and status quo bias. In both of the endowment effect and status quo bias experiments, no significant differences between emissions trading with and without consignment auction were observed. Thus, this study has not found any statistically significant evidence supporting that consignment auctions contribute to reducing cognitive biases.

\section{Conclusions and Future Directions}

This study tested whether the cognitive biases happen in the setting of emissions trading and showed that the cognitive biases occur in some situations. We also tested the effect of more experience and consignment auction on the cognitive biases. Contrary to conventional expectations, practitioner groups who were supposed to have more experience on emissions trading showed higher cognitive biases than the student group. In addition, despite the intuition that consignment auction may reduce the feeling of possession and make the status quo ambiguous, consignment auction also did not significantly mitigate the cognitive biases.

The cognitive bias may help partly explain the lack of transactions in emissions trading that is observed in the early stage of emissions trading schemes including Korea ETS and China ETS. Endowment effect would make companies have a stronger tendency to hold more of their acquired emission allowances than to sell them at proper prices. Status quo bias also make companies reluctant to do transactions. Then, the emissions trading market is subject to lack of supply and trading. The price of the allowance surges near the time to submit the emission permits. This is burdensome for companies to meet their targets by purchasing allowances and an authority makes some changes to the rules of emissions trading schemes in order to appease the companies complaining the high price and the lack of supply. Actually, this phenomenon occurred several times in Korea, where emissions trading was introduced in 2015.

The resulting lack of trading could hinder cost-effective greenhouse gas mitigation in general. Thus, it is important to know how to mitigate the cognitive bias in order to invigorate emissions trading. Because accumulation of experience and consignment auction did not significantly lower cognitive biases in this study, other methods to reduce cognitive biases should be developed. It is possible to think that decision-making structures and reward systems in an organization are important to make people in charge of emissions trading behave rationally. With respect to decision-making structures, the result of Chan and Saqib [36] should be noticed. They showed that the endowment effect 
occurs when people feel low power and argued that feeling powerful can reduce the endowment effect. This idea is worth testing in emissions trading situations. Further, Dean, Kıbris, and Masatlioglu [45], Gerasimou [49], and Tversky and Shafir [50] suggested decision avoidance concept to explain status quo bias. Decision avoidance means that if practitioners feel less difficulty in decision making, they will show less status quo bias. Some methods to reduce difficulty in decision making should be developed; such as more information about the market situation and government policy and education about emission trading. More studies about these issues are worth doing.

Finally, we mention a few limitations of this study and those will be helpful to make future research more valid. First, this study adopted a simple survey-based experiment rather than experiment using incentive-compatible mechanism such as auction or BDM (Becker-DeGroot-Marschak) method, in which all participants can achieve the best outcome to themselves just by acting according to their true preferences, to make the experiment mimic real-world trading. Even though designing incentive-compatible mechanisms which mimic real emission trading is difficult and costly, it will increase the validity of the results.

Second, another thing to be noticed is that the number of sample in each experiment is small. Even though most of survey-based experiments in the literature used $30 \sim 40$ subjects in each experiment as like this study, a higher number of subjects will increase the robustness of the results.

Third, the scenarios in the experiments are more or less abstract and did not fully reflect the real situation. It was to make the scenario easy to understand where subjects could focus on the main questions, specifically for the student group. However, development of more detailed scenario with the incentive compatible mechanism can be more realistic experiment. Further, the scenario of consignment auction is more complex than that of general emissions trading, which makes some inconsistency in comparing the results of emissions trading between the cases with and without consignment auction.

Fourth, this study showed that practitioners were more sensitive to the endowment effect and status quo bias, but the discussion about possible causes relied upon inferences rather than evidence. It also showed that status quo bias was significant only in the experiment with practitioners. These issues also need additional research.

Author Contributions: Conceptualization, J.-D.S. and Y.-H.A.; methodology, J.-D.S.; formal analysis, J.-D.S.; writing-original draft preparation, J.-D.S. and Y.-H.A.; writing—review and editing, Y.-H.A.; funding acquisition, Y.-H.A.

Funding: This work was supported by the Korea Energy Economics Institute (KEEI) grant funded by the South Korean Prime Minister's Office. The APC was also funded by the KEEI.

Acknowledgments: This paper is partly based on the results from the Korea Energy Economics Institute Research Report No. 2018-12. We also would like to thank two anonymous reviewers for their valuable comments and suggestions.

Conflicts of Interest: The authors declare no conflict of interest.

\section{References}

1. Coase, R. The problem of social cost. J. Law Econ. 1960, 3, 1-44. [CrossRef]

2. Montgomery, D.W. Markets in licenses and efficient pollution control programs. J. Econ. Theory 1972, 5, 395-418. [CrossRef]

3. Hahn, R.W.; Stavins, R.N. The Effect of Allowance Allocation on Cap-And-Trade System Performance, Unpublished Manuscript 15,854; National Bureau of Economic Research: Cambridge, MA, USA, 2010.

4. Kim, G.; Shim, S. Diagnosis and Improvement of Greenhouse Gas Emissions Trading System in Korea; Retrieved from Korea Energy Economics Institute: Ulsan, Korea, 2017; pp. 1-98.

5. Zhao, X.; Jiang, G.; Nie, D.; Chen, H. How to improve the market efficiency of carbon trading: A perspective of China. Renew. Sustain. Energy Rev. 2016, 59, 1229-1245. [CrossRef]

6. Kreutzer, J. Cap and trade: A behavioral analysis of the sulfur dioxide emissions market. NYU Annu. Surv. Am. Law 2006, 62, 125-162. 
7. Murphy, J.J.; Stranlund, J.K. A laboratory investigation of compliance behavior under tradable emissions rights: Implications for targeted enforcement. J. Environ. Econ. Manag. 2007, 53, 196-212. [CrossRef]

8. Shiloh, S.; Salto, E.; Sharabi, D. Individual differences in rational and intuitive thinking styles as predictors of heuristic responses and framing effects. Personal. Individ. Differ. 2002, 32, 415-429. [CrossRef]

9. Tversky, A.; Kahneman, D. Judgment under uncertainty: Heuristics and biases. Science 1974, 185, $1124-1131$. [CrossRef] [PubMed]

10. Burtraw, D.; Linn, J.; Palmer, K.L.; Paul, A.; McCormack, K.; Yin, H. Approaches to Address Potential CO Emissions Leakage to New Sources under the Clean Power Plan. RFF Report, Washington, DC, USA. 2016. Available online: http://www.rff.org/files/RFF-CPP-Technical-Background.pdf (accessed on 8 January 2019).

11. Burtraw, D.; McCormack, K. Consignment auctions of free emissions allowances. Energy Policy 2017, 107, 337-344. [CrossRef]

12. Perkis, D.F.; Cason, T.N.; Tyner, W.E. An experimental investigation of hard and soft price ceilings in emissions permit markets. Environ. Resour. Econ. 2016, 63, 703-718. [CrossRef]

13. Cason, T.N. What can laboratory experiments teach us about emissions permit market design? Agric. Resour. Econ. Rev. 2010, 39, 151-161. [CrossRef]

14. Kahneman, D.; Knetsch, J.L.; Thaler, R.H. Experimental test of the endowment effect and the Coase theorem. J. Polit. Econ. 1990, 98, 1325-1348. [CrossRef]

15. OECD/Eurostat. Treatment of Emissions Allowances and Emission Permits in the National Accounts. Final Report of OECD/Eurostat Task Force on the Treatment of Emissions Allowances and Emission Permits in the National Accounts. 2010. Available online: https://unstats.un.org/unsd/nationalaccount/docs/reportEP.pdf (accessed on 1 February 2019).

16. Braga, J.; Starmer, C. Preference anomalies, preference elicitation and the discovered preference hypothesis. Environ. Resour. Econ. 2005, 32, 55-89. [CrossRef]

17. List, J.A. Does market experience eliminate market anomalies. Q. J. Econ. 2003, 118, 41-70. [CrossRef]

18. Plott, C.R. Rational Individual Behavior in Markets and Social Choice Processes: The Discovered Preference Hypothesis. In The Rational Foundations of Economic Behaviour; McMillian: London, UK, 1996; pp. 225-250.

19. Plott, C.R.; Zeiler, K. The willingness to pay-willingness to accept gap, the "Endowment Effect," subject misconceptions and experimental procedures for eliciting valuations. Am. Econ. Rev. 2005, 95, 530-545. [CrossRef]

20. Plott, C.R.; Zeiler, K. The willingness to pay-Willingness to accept gap, the "Endowment Effect," subject misconceptions, and experimental procedures for eliciting valuations: Reply. Am. Econ. Rev. 2011, 101, 1012-1028. [CrossRef]

21. International Carbon Action Partnership (2019). USA-California Cap-and-Trade. Retrieved from International Carbon Action Partnership Website. Available online: https:/icapcarbonaction. $\mathrm{com} / \mathrm{ko} /$ ?option=com_etsmap\&task=export\&format=pdf\&layout=list\&systems[]=45. $\quad$ (accessed on 20 February 2019).

22. Hahn, R.W. Promoting efficiency and equity through institutional design. Policy Sci. 1988, 21, 41-66. [CrossRef]

23. Hahn, R.W.; Noll, R.G. Designing a Market for Tradable Emissions Permits. In Reform of Environmental Regulation; Magat, W., Ed.; Ballinger: Cambridge, MA, USA, 1982; pp. 119-146.

24. Khezr, P.; MacKenzie, I.A. Consignment auctions. J. Environ. Econ. Manag. 2018, 87, 42-51. [CrossRef]

25. Horowitz, J.K.; McConnell, K.E. A review of WTA/WTP studies. J. Environ. Econ. Manag. 2002, 44, $426-447$. [CrossRef]

26. Knetsch, J.L.; Sinden, J.A. Willingness to pay and compensation demanded: Experimental evidence of an unexpected disparity in measures of value. Q. J. Econ. 1984, 99, 507-521. [CrossRef]

27. Kahneman, D.; Knetsch, J.L.; Thaler, R.H. Anomalies: The endowment effect, loss aversion, and status quo bias. J. Econ. Perspect. 1991, 5, 193-206. [CrossRef]

28. Frenkel, S.; Heller, Y.; Teper, R. The endowment effect as blessing. Int. Econ. Rev. 2018, 59, 1159-1186. [CrossRef]

29. Peñón, I.E.; Ortega, S.R. The endowment effect on entrepreneurs: A risky attachment. Estudios Econ. 2018, 45, 231-249. [CrossRef]

30. Novemsly, N.; Kahneman, D. The boundaries of loss aversion. J. Mark. Res. 2005, 42, 119-128. [CrossRef] 
31. Chan, E.Y. Endowment effect for hedonic but not utilitarian goods. Int. J. Res. Mark. 2015, 32, $439-441$. [CrossRef]

32. Saqib, N.U.; Frohlich, N.; Bruning, E. The influence of involvement on the endowment effect: The moveable value function. J. Consum. Psychol. 2010, 20, 355-368. [CrossRef]

33. Lerner, J.S.; Small, D.A.; Loewenstein, G. Heart strings and purse strings: Carryover effects of emotions on economic decisions. Psychol. Sci. 2004, 15, 337-341. [CrossRef] [PubMed]

34. Martinez, L.F.; Zeelenberg, M.; Rijsman, J.B. Regret, disappointment and the endowment effect. J. Econ. Psychol. 2011, 32, 962-968. [CrossRef]

35. Zhang, Y.; Fishbach, A. The role of anticipated emotions in the endowment effect. J. Consum. Psychol. 2005, 15, 316-324. [CrossRef]

36. Eugene, C.; Najam, S. Reversing the endowment effect by empowering buyers and sellers. Eur. J. Mark. 2018, 52, 1827-1844. [CrossRef]

37. List, J.A. Neoclassical theory versus prospect theory: Evidence from the marketplace. Econometrica 2004, 72, 615-625. [CrossRef]

38. Knetsch, J.L. The endowment effect and evidence of nonreversible indifference curve. Am. Econ. Rev. 1989, $79,1277-1284$.

39. Hambrick, D.C. Upper echelons theory: An update. Acad. Manag. Rev. 2007, 32, 334-343. [CrossRef]

40. Hambrick, D.C.; Mason, P.A. Upper echelons: The organization as a reflection of its top managers. Acad. Manag. Rev. 1984, 9, 193-206. [CrossRef]

41. Samuelson, W.; Zeckhauser, R. Status quo bias in decision making. J. Risk Uncertain. 1988, 1, 7-59. [CrossRef]

42. Hartman, R.S.; Doane, M.J.; Woo, C. Consumer rationality and the status quo. Q. J. Econ. 1991, 106, 141-162. [CrossRef]

43. Li, J.; Liu, M.; Liu, X. Why do employees resist knowledge management systems? An empirical study from the status quo bias and inertia perspectives. Comput. Hum. Behav. 2016, 65, 189-200. [CrossRef]

44. Zhang, X.; Guo, X.; Wu, Y.; Lai, K.; Vogel, D. Exploring the inhibitors of online health service use intention: A status quo bias perspective. Inf. Manag. 2017, 54, 987-997. [CrossRef]

45. Dean, M.; Kıbrıs, Ö.; Masatlioglu, Y. Limited attention and status quo bias. J. Econ. Theory 2017, 169, 93-127. [CrossRef]

46. Kempf, A.; Ruenzi, S. Status quo bias and the number of alternatives: An empirical illustration from the mutual fund industry. J. Behav. Financ. 2006, 7, 204-213. [CrossRef]

47. Ashforth, B.E.; Lee, R.T. Defensive behavior in organizations: A preliminary model. Hum. Relat. 1990, 43, 621-648. [CrossRef]

48. Veiga, J.F. The frequency of self-limiting behavior in groups: A measure and an explanation. Hum. Relat. 1991, 44, 877-895. [CrossRef]

49. Gerasimou, G. Asymmetric dominance, deferral, and status quo bias in a behavioral model of choice. Theory Decis. 2016, 80, 295-312. [CrossRef]

50. Tversky, A.; Shafir, E. Choice under conflict: The dynamics of deferred decision. Psychol. Sci. 1992, 3, 358-361. [CrossRef]

(C) 2019 by the authors. Licensee MDPI, Basel, Switzerland. This article is an open access article distributed under the terms and conditions of the Creative Commons Attribution (CC BY) license (http://creativecommons.org/licenses/by/4.0/). 